\title{
A NOTE ON A GAMMA FUNCTION INEQUALITY
}

\section{PÉTER IVÁDY}

Abstract. The aim of this article is to present new inequalities which improve some gamma function inequalities of H. Alzer, Á. Baricz and N. Elezović et al.

Mathematics subject classification (2000): 26D07, 33B15.

Keywords and phrases: gamma function, psi function, inequalities, convex functions, Jensen's inequality.

\section{REFERENCES}

[1] H. AlZER, On some inequalities for the gamma and psi functions, Math. Comput., 66 (1997), $373-$ 389.

[2] G. D. Anderson, M. K. Vamanamurthy and M. Vuorinen, Conformal invariants, inequalities, and quasiconformal maps, Wiley, New York, 1997.

[3] G. E. Andrews, R. Askey And R. Roy, Special functions, Cambridge Univ. Press, Cambridge, 1999.

[4] Á. BARICZ, Redheffer type inequality for Bessel functions, J. Inequal. Pure Appl. Math., 8(1) (2007), 220-226.

[5] N. Elezović, C. Giordano And J. PeČArić, The best bounds in Gautschi's inequality, Math. Inequal. Appl., 3 (2000), 239-252.

[6] W. GAUTSCHI, Some elementary inequalities relating to the gamma and incomplete gamma function, J. Math. Phys., 38 (1959), 77-81.

[7] W. GaUTSCHI, The incomplete gamma function since Tricomi. In Tricomi's ideas and contemporary applied mathematics. Atti Convengi Lincei, vol. 147, (1998), 203-237 (Rome: Accad. Naz. Lincei).

[8] L. Gordon, A stochastic approach to the gamma function, Amer. Math. Monthly, 101 (1994), 858865.

[9] D. Kershaw, Some extensions of W. Gautschi's inequalities for the gamma function, Math. Comp., 41 (1983), 607-611.

[10] A. Ralston, A First Course in Numerical Analysis, McGraw-Hill, New York, 1965.

[11] D. S. Mitrinović, Analytic Inequalities, Springer, 1970.

[12] D. S. Mitrinović, J. PeČArić, And A. M. Fink, Classical and New Inequalities in Analysis, Kluwer Academic, Dordrecht/Boston/London, 1993. 